\title{
Examining the Nova Scotia Science Curriculum for International Ocean Literacy Principle Inclusion
}

\author{
Kerri McPherson \\ School for Resource and Environmental Studies \\ Dalhousie University, Canada \\ Dr. Tarah Wright \\ Environmental Science \\ Dalhousie University, Canada \\ Dr. Peter Tyedmers \\ School for Resource and Environmental Studies \\ Dalhousie University, Canada
}

\begin{abstract}
Within Nova Scotia the ocean has an integral role in the economy and culture of the province. Nova Scotia is home to abundant marine resources and a rapidly developing ocean technology sector. Despite the importance of this resource and access to resources, youth in Nova Scotia have exhibited low knowledge of basic ocean concepts. This study investigates the extent to which the internationally established Ocean Literacy Principles are included in the curriculum outcomes of the Nova Scotia high school science curriculum. Data analysis of all high school science curriculum documents were guided by the seven Ocean Literacy Principles and the supporting fundamental concepts. Results from this study reveal limited inclusion of ocean concepts throughout the high school science curriculum. The effect of the diminished and marginalized inclusion of ocean education is the production of individuals with limited knowledge of basic ocean principles, who are ill prepared to make informed decisions regarding the health of the ocean and the future of Nova Scotia.
\end{abstract}

Keywords: Ocean Literacy; Ocean Literacy Principles; Ocean Education; Education; Curriculum.

\section{Introduction}

Studies have found that in general the public has limited understanding of concepts related to ocean literacy, ultimately impacting the ability to make 
informed decisions regarding the overall health of the ocean (Belden et al., 1999; Eddy, 2014; Fletcher \& Potts, 2009; Guest, Lotze \& Wallace, 2015; Plankis \& Marrero, 2010). In addition, research has indicated that significant knowledge gaps exist between public perception of marine environmental issues and the actual threats to the marine environment (Eddy, 2014). Education on critical issues pertaining to the ocean has the potential to engage individuals in behaviours that are less destructive to the ocean environment, and to aid in the capacity for creative solutions (Steel et al., 2005b). In addition, lack of knowledge on these issues has the potential to increase negative impacts on the oceanic environment due to higher levels of ignorance (Uyarra \& Borja, 2016). Without education that provides a strong connection to, and understanding of, ocean processes and the consequences of human actions on the oceans themselves, changes in attitudes and positive action toward the ocean that develop into sustainable behavior are unlikely to occur (Guest et al., 2015; Steel et al., 2005b; Tran, Payne, Whitley, 2010). This study sought to better understand the extent to which the internationally established Ocean Literacy Principles are included within the Nova Scotia high school science curriculum.

\section{Ocean Literacy}

In the late 1990's, the publication of the American National Science Education Standards caught the attention of several marine scientists. The published Education Standards contained little to no mention of the ocean or ocean concepts and as a result ocean science was largely left out of classroom teaching from kindergarten to grade 12 (Schoedinger, Tran \& Whitley, 2010). Ocean scientists reacted quickly, developing the Ocean Literacy Campaign as a strategy to bring key ocean concepts into the education system and ultimately into the classrooms. The Ocean Literacy Campaign, a collaborative effort between scientists and educators focused on creating a more ocean literate society, was developed as a strategy to bring key ocean concepts into the education system and classrooms (Schoedinger et al., 2010). Ocean literacy is defined as "an understanding of the ocean's influence on you and your influence on the ocean" (Cava, Schoedinger, Strang, \& Tuddenham, 2005, p 5). Someone who is ocean literate is able to understand fundamental ocean concepts and principles, can communicate about ocean issues and can make informed, responsible decisions regarding the ocean and ocean resources (Cava et al., 2005). The Ocean Literacy Campaign established seven essential principles of ocean literacy encompassing the ocean knowledge required for ocean literacy (See Table 1). The principles were developed to provide educators and curriculum developers with a "roadmap" to build ocean centered relevant learning experiences (Schoedinger et al., 2010). Each of the essential principles are further broken down into smaller Fundamental Concepts, offering more specific criteria that relates to each of the individual principles (Ocean Literacy Network, 2013).

Despite the strategies of the Ocean Literacy Campaign, ocean concepts remain difficult to find in the curriculum of most countries (Gough, 2017). Castle, Fletcher and McKinley (2010) noted that the perceived lack of ocean content contained in England's curriculum had been significantly criticized. On further 
analysis of England's curriculum, Gough (2017) states that neither of the terms "coastal" or "marine" appear within the science curriculum. New Zealand's science curriculum also came up short on the inclusion of ocean concepts, with the same two terms "ocean" and "marine" being absent (Gough, 2017). An analysis of the Australian curriculum revealed minimal references to ocean related content (Gough, 2017), and Berchez et al. (2016) reported similar findings on the inclusion of environmental-education activities in Brazil. A report analyzing the earth science education standards within the 50 United States conducted by Hoffman and Barstow (2007) found that Ocean Literacy Principles are not commonly implemented, with most states only including minimal references, and three not addressing any of the Ocean Literacy Principles. None of the state education standards examined received a grade higher than a $\mathrm{C}$ on their inclusion of Ocean Literacy Principles (Hoffmann \& Barstow, 2007).

Within Canada, a formal ocean education framework including the entire country does not exist. The Canadian government does convene a Council of Ministers of Education (CMEC) that exists with the goal of promoting discussion and collaboration among the; 10 provinces and 3 territories (CMEC, 2001), but curriculum is specifically set by each province/territory. Each individual school system is designed to reflect the unique cultural and historical heritage and to reflect issues of importance specific to that region (CMEC, 2001). It can be argued that oceans education is relevant for all provinces, whether bordered by the ocean or not, as the ocean has a major impact on weather, climate and the water table (Hoffman \& Barstow, 2007; Strang, 2008). However, not all provinces put ocean education as a priority area for their curriculum. In fact, research examining educational curriculum from British Columbia, another coastal province, found that ocean concepts are generally lacking (Cummins \& Snively, 2000; Gough, 2017). Further research indicates that Canada has made little progress in developing oceans education (UNESCO, 2014; Guest et al., 2015; Scully, 2015; Scully 2016).

Within the province of Nova Scotia, the ocean has an integral role in the economy and heritage of the province (Scully, 2015). The ocean industry in Nova Scotia is growing and encompasses an abundance of ocean related services including; fisheries (commercial and recreational), aquaculture, offshore hydrocarbon energy projects, tidal energy, ports, shipyards, research, tourism, among many more and in addition to countless recreation opportunities (Province of Nova Scotia, 2011). Yet, despite potential access to these resources, youth in Nova Scotia have achieved low scores in knowledge on ocean concepts (Guest et al., 2015). A study of Nova Scotia youth found that despite a high proportion (96\%) indicating that they valued the ocean, they were unable to answer general knowledge questions about the ocean (average scores of less than 50\%), indicating that youth in Nova Scotians are not adequately educated on basic ocean concepts (Guest et al., 2015). These results imply that education efforts need to be improved in order to increase student understanding of ocean concepts. 


\section{Methods}

This research involved an in-depth analysis of the Nova Scotia high school science curriculum documents in order to determine the extent to which ocean education is included in Nova Scotia's high school science courses and to determine how the context relates to the seven principles of ocean literacy. The curriculum documents used for the Nova Scotia high school science courses are part of the Atlantic Canada Science Curriculum, developed regionally so as to create consistent science curriculum across the four Atlantic Canadian Provinces (APEF, 1998). Science curriculum within the Atlantic Provinces is primarily focused on the development of scientific literacy among all students through the three fundamental processes of scientific inquiry, problem solving and decisionmaking (APEF, 1998).

Structurally, science curriculum documents are based on an outcome framework that consists of essential graduation learnings, general curriculum outcomes, and specific curriculum outcomes (Council of Ministers Education, 1997). The essential graduation learnings are not subject specific, but are broad statements reflecting the knowledge, skills and attitudes expected of those students graduating from secondary school (Council of Ministers Education, 1997). General curriculum outcomes (GCO's) have been divided into categories that encompass the key components of scientific literacy and provide the overall categories and basis for the outcomes framework (APEF, 1998). The four categories include: Science, Technology, Society and the Environment (STSE), Skills, Knowledge, and Attitudes are consistent throughout all science curriculum documents within Nova Scotia. Specific curriculum outcomes are intended to reflect content that is specific to each individual course. The outcome statements indicate what each student is expected to know upon course completion. The outcomes are designed to direct educators in developing learning experiences and assessment tools that are appropriate for the intended course and assist students in achieving the general curriculum outcomes and essential graduation learnings (APEF, 1998). In this study, only the curriculum outcomes for each of the 11 curriculum documents were coded based on the belief that the outcomes are what direct teaching practices. Specific curriculum outcomes inform what is to be taught within the course and are supported by suggested strategies and techniques throughout the curriculum document. As the outcomes are the only section explicit to teaching instruction they are the focus of this study.

The categories from the general curriculum outcomes, knowledge, skills and STSE were selected for analysis. These categories are represented within the specific curriculum outcome framework which facilitated the ability to determine where ocean concepts are strongly represented and where they are lacking. The attitudes category was not selected for analysis as the focus of this aspect, responsible acquisition and application of scientific and technological knowledge (APEF, 1998), can be achieved through the analysis of the knowledge and STSE categories. In addition, the specific curriculum outcomes emphasize knowledge, skills and STSE, as such the attitudes category would not be specifically addressed in the outcomes framework. 
High school science curriculum documents used within this study were accessed through the Nova Scotia's Department of Education website's "Document Depot". All eleven science documents $(n=11)$ were analysed including; Science 10, Biology 11 and 12, Chemistry 11 and 12, Physics 11 and 12, Human Biology 11, Oceans 11, Food Science 12 and Geology 12. Prior to analysis, curriculum documents were imported into NVivo 10, a qualitative data analysis program created by QSR International that allows the researcher to organize and find insights and connections within qualitative data (QSR International, 2017).

\section{Data Analysis}

The analysis of the documents was guided by the seven principles for ocean literacy. Curriculum outcomes were initially coded using the a priori codes established from the Ocean Literacy Principles and the Fundamental Concepts. From the initial analysis, the quantity of ocean education was determined by calculating the number of outcomes within each document that were categorized within the established Principles. There were many outcomes that were coded by multiple Principles. In order to determine the context of the ocean education, the coded outcomes were further analysed and categorized into sub-codes based on the Fundamental Concepts, also developed a priori. Several outcomes reflected multiple Fundamental Concepts, indicating areas where Ocean Literacy Principles would be included. Coding the outcomes into sub-codes gave deeper insight into where the key concepts from the Ocean Literacy Principles would be addressed within each of the curriculum documents.

\section{Results and Discussion}

This study found that the Ocean Literacy Principles are represented in some capacity within the cadre of courses available to students in Nova Scotia, with the exception of Principle 7, which was not included within the science curriculum. It is pertinent to note that 8 of the 11 courses make no mention of the Ocean Literacy Principles within their curriculum. Principles included in each of the 11 courses are represented in Figure 1. 


\section{Quantity of Ocean Education}

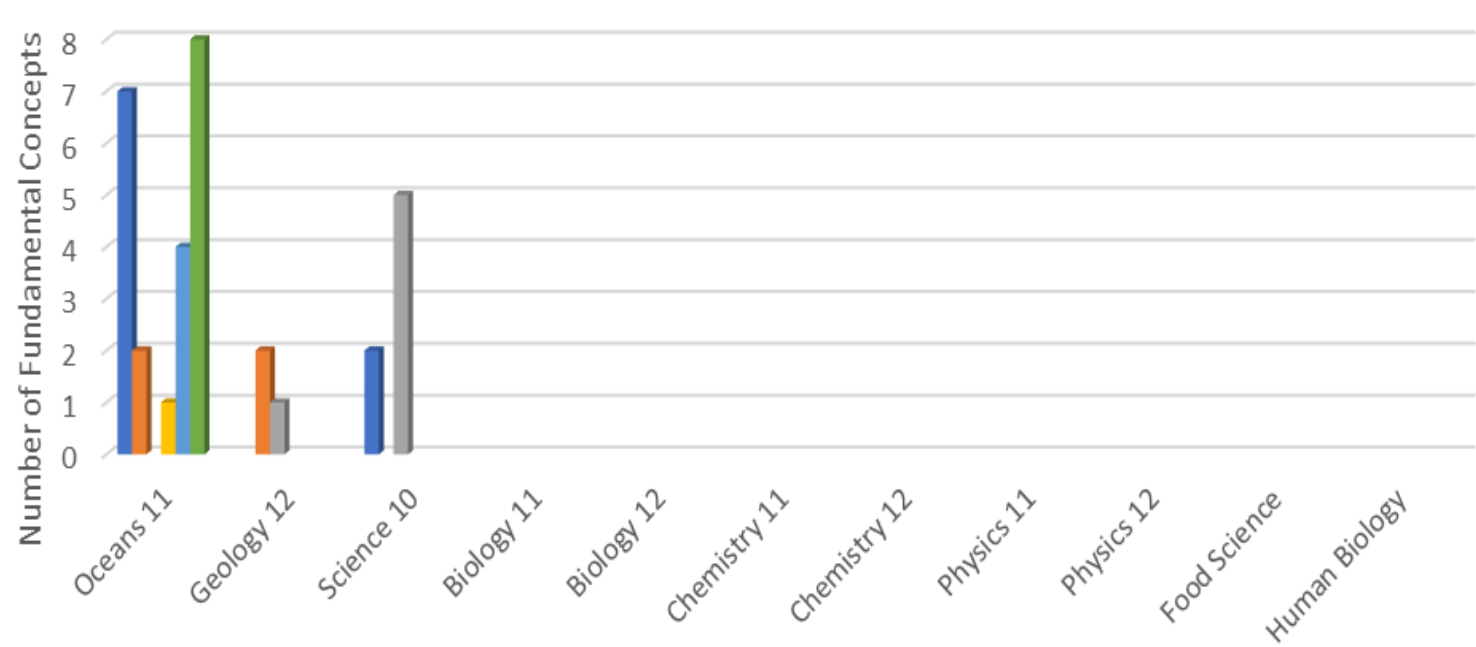

- Principle 1: One big ocean

- Principle 2: Ocean shapes features of earth

- Principle 3: Ocean influences weather and climate 1 Principle 4: The ocean made earth habitable

- Principle 5: The ocean supports diversity

- Principle 6: Oceans and humans are connected

- Principle 7: The ocean is largely unexplored

Figure 1: Quantity of Ocean Education relating to the Ocean Literacy Principles Inclusion of the Ocean Literacy Principles within Science Curriculum

While six of the seven Ocean Literacy Principles are represented with the science curriculum, on further examination it was found that the majority of the supporting Fundamental Concepts are absent. Table 1 illustrates the degree to which the Fundamental Concepts for each Ocean Literacy Principle are included within the three science curriculum documents that referenced the Ocean Literacy Principles. 
Table 1: Fundamental Concepts in Science Curriculum

\begin{tabular}{|c|c|c|c|c|}
\hline Ocean Literacy Principle & Fundamental Concept (FC) & Oceans 11 & Geology 12 & Science 10 \\
\hline \multirow{8}{*}{$\begin{array}{l}\text { 1. The earth has one big ocean } \\
\text { with many features }\end{array}$} & $\mathrm{A}$ & $\checkmark$ & & \\
\hline & B & $\checkmark$ & & \\
\hline & C & $\checkmark$ & & \\
\hline & $\mathrm{D}$ & & & \\
\hline & $\mathrm{E}$ & $\checkmark$ & & \\
\hline & $\mathrm{F}$ & & & $\checkmark$ \\
\hline & G & $\checkmark$ & & \\
\hline & $\mathrm{H}$ & & & \\
\hline \multirow{5}{*}{$\begin{array}{l}\text { 2. The ocean and life in the } \\
\text { ocean shape the features of } \\
\text { earth }\end{array}$} & $\mathrm{A}$ & & & \\
\hline & $\mathrm{B}$ & & & \\
\hline & $\mathrm{C}$ & $\checkmark$ & $\checkmark$ & \\
\hline & $\mathrm{D}$ & & & \\
\hline & $\mathrm{E}$ & & & \\
\hline \multirow{7}{*}{$\begin{array}{l}\text { 3. The ocean is a major } \\
\text { influence on weather and } \\
\text { climate. }\end{array}$} & $\mathrm{A}$ & & $\checkmark$ & $\checkmark$ \\
\hline & B & & & $\checkmark$ \\
\hline & $\mathrm{C}$ & & & $\checkmark$ \\
\hline & $\mathrm{D}$ & & & \\
\hline & $\mathrm{E}$ & & & \\
\hline & F & & & $\checkmark$ \\
\hline & G & & & \\
\hline \multirow{3}{*}{$\begin{array}{l}\text { 4. The ocean made earth } \\
\text { habitable. }\end{array}$} & $\mathrm{A}$ & & & \\
\hline & $\mathrm{B}$ & $\checkmark$ & & \\
\hline & $\mathrm{C}$ & & & \\
\hline \multirow{9}{*}{$\begin{array}{l}\text { 5. The ocean supports a great } \\
\text { diversity of life and } \\
\text { ecosystems }\end{array}$} & $\mathrm{A}$ & & & \\
\hline & B & $\checkmark$ & & \\
\hline & $\mathrm{C}$ & & & \\
\hline & $\mathrm{D}$ & $\checkmark$ & & \\
\hline & $\mathrm{E}$ & & & \\
\hline & $\mathrm{F}$ & & & \\
\hline & G & $\checkmark$ & & \\
\hline & $\mathrm{H}$ & $\checkmark$ & & \\
\hline & I & $\checkmark$ & & \\
\hline \multirow{7}{*}{$\begin{array}{l}\text { 6. The ocean and humans are } \\
\text { inextricably interconnected }\end{array}$} & A & & & \\
\hline & $\mathrm{B}$ & $\checkmark$ & & \\
\hline & $\mathrm{C}$ & $\checkmark$ & & \\
\hline & $\mathrm{D}$ & $\checkmark$ & & \\
\hline & E & $\checkmark$ & & \\
\hline & F & $\checkmark$ & & \\
\hline & G & $\checkmark$ & & \\
\hline \multirow{6}{*}{$\begin{array}{l}\text { 7. The ocean is largely } \\
\text { unexplored. }\end{array}$} & $\mathrm{A}$ & & & \\
\hline & B & & & \\
\hline & $\mathrm{C}$ & & & \\
\hline & $\mathrm{D}$ & & & \\
\hline & $E$ & & & \\
\hline & $F$ & & & \\
\hline
\end{tabular}


Science 10. Science 10 is the only mandatory science credit that must be completed by all students in high school to meet graduation requirements. The course is divided into four equally weighted units including; weather dynamics, chemical reactions, motion and sustainability of ecosystems. Science 10 has sixty-nine outcomes and the analysis shows that only seven of the sixty-nine outcomes reference the topics encompassed by the Oceans Literacy Principles. Further examination identifies that those seven outcomes are situated within the confines of Principle 1 and Principle 3. Principle 1 and Principle 3 were further broken down to identify how many Fundamental Concepts associated with each Principle are touched upon. Within Principle 1, only one of the fundamental concepts associated with this principle (out of a possible 8) is covered and Principle 3 addressed four of a possible seven fundamental concepts. In addition, of the Science 10 curriculum outcomes that do address the Ocean Literacy Principles all are found exclusively within the weather dynamics unit and are related specifically to knowledge outcomes alone. While it is essential for students to understand concepts from the knowledge category, the skills and STSE categories focus on collaboration and the social and environmental contexts of science and technology (APEF, 1998). These findings demonstrate that the overall coverage of the Ocean Literacy Principles and Fundamental Concepts is not robust in the Nova Scotia Science 10 curriculum.

It is interesting to note which Ocean Literacy Principles and Fundamental Concepts are not represented in the Science 10 curriculum. For example, while there are two outcomes related to Principle 1, both are encompassed within Fundamental Concept F, the other Fundamental Concepts including the ocean as a prominent feature of the earth and the connectedness to lakes and waterways, geological features, global circulation, composition of seawater, sea level and finite resources are not mentioned. A prior survey on ocean literacy among Nova Scotian youth found that questions pertaining to the causes of sea level rise received the highest proportion of incorrect answers (Guest et al., 2015). In addition, Guest et al. (2015) state that students often confused concepts, explaining one concept using knowledge they had acquired on a related topic resulting in misconceptions. For example, students mistakenly associated sea level rise with the motion of tides, along with believing that high tides were a result of high waves (Guest et al., 2015). Findings of students making similar mistakes have also been noted in studies from the United States (Brody \& Koch, 1990) and South Africa (Ballantyne, 2004). The lack of inclusion of the concepts from the first ocean literacy principle corresponds to studies indicating that youth have limited understanding of basic ocean processes (Guest et al., 2015; Plankis \& Marrero, 2010).

Another example where Fundamental Concepts are absent from the Science 10 curriculum is clear in the coverage of Principle 3 that focuses on the ocean as a major influence on weather and climate. The weather dynamics unit covers Principle 3 to some extent, with five outcomes situated within four of the Foundational Concepts. Topics include the moderating effect of oceans on weather and climate and the impacts of heat exchange on climate change and weather phenomenon. However, Fundamental Concepts D, E, and G are not included in the Science 10 curriculum, and main concepts that are not addressed 
in the curriculum include the role of the ocean and the water cycle in the formation of hurricanes and severe storms, impacts of a changing oceanatmosphere system, the role of the ocean in the carbon cycle and the significance of ocean primary productivity. The lack of inclusion of significant issues has the potential to exacerbate misconceptions and the ability of graduates to make informed decisions. A study conducted for the Ocean Project (1999) (Belden et al., 1999), found that while most individuals in the United States, were able to identify climate change as one of the most prominent environmental issues, many did not associate climate change with the ocean.

It is also of particular interest that there is no mention of pollution or significance of human impacts (Principle 6) in the Science 10 curriculum, which are two critical components in raising student comprehension and awareness of ocean issues. Several studies have indicated that most individuals exhibit a concern for ocean health; however fewer individuals are able to recognize the impacts of their own personal actions (Plankis \& Marrero, 2010; Steel et al., 2005a). In addition, Steel et al. (2005a) found that amongst citizens of the United States, a strong relationship exists between level of ocean knowledge and the degree of support given to ocean restoration projects. Higher levels of knowledge and awareness of critical ocean issues are associated with heightened levels of marine citizenship, resulting in individuals feeling that they have a responsibility to act sustainably (Fletcher \& Potts, 2007; McKinley \& Fletcher, 2012).

Finally, it is important to identify that the unit focused on the sustainability of ecosystems contains no reference to any of the established international Ocean Literacy Principles and makes no direct mention of ocean education. The unit focuses on sustainability as a concept and aims to develop student connection to local environments and economy, deepening global thinking and decisionmaking (Nova Scotia Department of Education, 2012b). Given that the science curriculum was designed as an Atlantic Canadian framework, the proximity of Atlantic Canada to the ocean, and the impact of the ocean on both Nova Scotia livelihoods and the economy, it is surprising that none of the Principles are mentioned.

Geology 12. Geology 12 is an elective science course offered at most high schools within Nova Scotia. The course is divided into six units including; nature of geology, Earth's materials, internal processes, surface processes, historical geology and environmental geology. Geology 12 has eighty-one outcomes that teachers are expected to address. Analysis of the curriculum found that only Principle 2 and Principle 3 were addressed within the curriculum. Further analysis indicated that for Principle 2, only one fundamental concept was addressed out of a possible five. Similarly, from a potential seven fundamental concepts within Principle 3 only one was covered in the curriculum. Our findings indicate that the overall inclusion of the Principles and Fundamental Concepts within the Geology 12 curriculum is minimal.

Similar to Science 10, the outcomes that specifically reference the Principles and Fundamental Concepts are found exclusively within one unit, the surface 
processes unit. Concepts incorporated in Principle 2, such as the process of erosion and factors, such as wind, waves and currents that can cause surfaces to erode at a faster rate, align with the Geology 12 curriculum. However, it is interesting to note that there is no mention of ocean bathymetry or tectonic activity referring to the ocean, such as sea floor spreading, and the relation to the development of landforms. Tectonic activity in the ocean has a direct impact of features on land, understanding these processes is critical in understanding formation of geological features. Guest et al. (2015) found that knowledge gaps were common amongst Nova Scotian youth in topics related to the physical ocean, and scores were typically lower on questions that involved connections between the Earth's systems. In addition, all of the references to the Ocean Literacy Principles are found solely within the knowledge category, with no inclusion of the skills or STSE categories.

Oceans 11. Oceans 11 is an elective science course offered at most high schools within Nova Scotia and is the only course that has a focus specifically on ocean education. The course is divided into five units, four of which are required for the completion of the course. The three compulsory units include; structure and motion, marine biomes, and coastal zones. Educators have the option of studying fisheries or aquaculture, for the fourth unit depending on which unit they feel is more relevant to their students based on interest, school or community (Nova Scotia Department of Education, 2012a). Oceans 11 is designed to give students an introduction to basic ocean concepts and to develop student understanding on the complex issues of ocean and resource management. The course presents current issues pertaining to ocean health and offers students the opportunity to learn about emerging technologies and ocean related career opportunities (Nova Scotia Department of Education, 2012a).

An analysis of the Oceans 11 curriculum indicated that all Principles were included, with the exception, of Principles 3 and 7. Oceans 11 has twenty-eight outcomes, and this study found that twenty curriculum outcomes specifically referenced the Ocean Literacy Principles, within all units of study, referencing all categories (knowledge, skills, STSE) of the outcome framework. Further analysis found that Principle 6 was the most represented within the Oceans 11 curriculum achieving all Fundamental Concepts with the exception of one. Principle 6 pertains to the human connection to the ocean. Prior studies have found individuals to be generally interested in the ocean and view the ocean as important, however their knowledge and connection of personal actions tend to be low (Belden et al. 1999; Cummins \& Snively, 2000; Guest et al., 2015; Plankis \& Marrero, 2010). With a strong focus on human connections to the ocean, such as discussing sustainable fisheries and human impacts through pollution and waste, the Oceans 11 course helps to develop student awareness and fill gaps in knowledge.

Principle 1 and Principle 5 also included many specific references, with Principle 1 including five out of the potential eight Fundamental Concepts and Principle 5 containing five of the nine Fundamental Concepts. Principle 1 addresses concepts on the importance of the ocean, the geological features of the ocean, tides and currents, the structure of water, and the connectivity between watersheds and the ocean are included within the structure and motion unit. 
Prior research in Nova Scotia has identified that knowledge in this area is recognized as needing development (Ballantyne, 2004; Guest et al., 2015; Plankis \& Marrero, 2010). Principle 5 addresses food webs, feeding levels, levels of biodiversity, interconnectedness within the marine biome, and the diversity of marine environments. Topics centered around marine animals and life in the ocean draw more engagement from students and studies have shown that youth are more knowledgeable in these areas (Ballantyne, 2004; Guest et al., 2015). Principle 2 and Principle 4 were not as widely included, with only one Fundamental Concept from each principle included within the Oceans 11 curriculum.

\section{Gaps in the Inclusion of Ocean Literacy}

As a course designed to deepen student understanding of basic ocean education, and as a science course with an objective of developing scientific literacy, the Oceans 11 course does a respectable job in providing information. Of the three compulsory units, all outcomes, apart from one from the coastal zones unit, are aligned with the Ocean Literacy Principles. While this represents a strong correlation, there are still many of the Fundamental Concepts that are not included in the Oceans 11 curriculum and several of the outcomes do not relate to any of the Ocean Literacy Principles.

An analysis of Principle 1 indicated that Fundamental Concepts D, F and H were absent from the Oceans 11 curriculum. Further research found that Fundamental Concept D, which addresses factors that impact changes to sea level, is not only absent from the Oceans 11 curriculum but from all high school science curriculum. It has been well documented that knowledge is low and considerable misconceptions exist in understanding concepts from the first ocean literacy principle (Ballantyne, 2004; Brody \& Koch, 1990; Guest et al., 2015; Plankis \& Marrero, 2010). The lack of inclusion of these concepts in the Oceans 11 curriculum support these findings and implies that students are not receiving the skills to be considered ocean literate in this principle.

Research has shown that systems thinking at the junior high and high school level is challenging, and that making connections between the Earth's systems, land, atmosphere, and ocean, are difficult for students (Assaraf \& Orion, 2004). Fundamental Concept $\mathrm{F}$ illustrates the integral role the ocean has in the water cycle; the absence of this principle from the Oceans 11 curriculum misses an opportunity to examine the connection between Earth systems. Principle 4 also addresses the connection between Earth systems. Fundamental Concept A, which identifies the importance of nutrient cycles and photosynthetic marine life, is not directly referenced within the curriculum. Research indicates that while youth value the ocean, mainly for recreation use, Guest et al. (2015) noted that only $42 \%$ of youth surveyed recognized the ocean as a source of atmospheric oxygen and $23 \%$ identified climate regulation as being important. The absence of these concepts from the science curriculum misses a critical link in student comprehension. It is essential for individuals to have knowledge about the ocean, such as being responsible for half of the Earth's primary productivity and free oxygen in the atmosphere, so that they can make connections to the impacts of their actions and in order to understand the 
resulting consequences of changes to the ocean-atmosphere system (McKinley \& Fletcher, 2012).

Our analysis found that the Fundamental Concepts of Principle 2 were largely lacking from the Oceans 11 curriculum, with the exception of Fundamental Concept C, which was included in both the Oceans 11 and Geology 12 curriculum. Principle 2 incorporates biogeochemical and carbon cycles, aiding in the development of a deeper understanding of the composition and cyclic nature of our earth. Guest et al. (2015) found that questions pertaining to the chemical nature of the ocean, including salinity and ocean acidification, received low scores and when given the option students chose not to answer those questions, indicating a lack of understanding of concepts.

While Principle 3 is absent from the Oceans 11 curriculum it is well represented within the Science 10 curriculum. However, the Fundamental Concepts relating to the carbon cycle and changes within the ocean-atmosphere system (Fundamental Concepts $3 \mathrm{E}$ and $3 \mathrm{G}$ ) are not represented in any high school science curriculum. Knowledge of the carbon cycle is essential in understanding current global issues, such as climate change and ocean acidification, and the impacts that these issues will have on communities and individuals. Clear links have been established between climate change, carbon pollution and the health of the ocean, including the connection between decreasing oceanic $\mathrm{pH}$, reduction of oceanic productivity and alteration of food web dynamics (Plankis \& Marrero, 2010). Several studies have indicated that low knowledge of ocean concepts combined with an inability to connect global issues to ocean processes results in individuals who are not engaged in marine citizenship or are invested in ocean related protection (Fletcher \& Potts, 2007; McKinley \& Fetcher, 2012).

The findings of this study indicate that all Fundamental Concepts from Principle 7 were completely absent from not only the Oceans 11 curriculum but from all of the reviewed high school science curriculum documents. Principle 7 focuses on the interdisciplinary nature of ocean science and the importance of understanding of ocean systems, not simply for curiosity but for survival (Ocean Literacy Network, 2013). Many of the Fundamental Concepts (7B, 7D, and 7F) have a focus on new and innovative technology for ocean exploration, and for youth in Nova Scotia the exclusion of this principle is a significant concern. The ocean technology sector within Nova Scotia is growing rapidly, doubling revenues between 2003 and 2009 to \$500,000,000 (Province of Nova Scotia, 2011). The Oceans 11 curriculum document states that significant time is to be designated to learning about local economic and community interests, including the development of new economies and opportunities (Nova Scotia Department of Education, 1998). While the curriculum does include references to ocean industry, including units on fisheries and aquaculture, there is no mention of ocean technology within the outcomes. Studies have indicated that Nova Scotian youth do not have a strong awareness of job opportunities and careers available within the ocean sector, less than half of the youth surveyed expressed an interest in ocean related careers (Guest et al., 2015, Scully, 2016). The inclusion of ocean related industries and career information in Nova Scotia science curriculum may contribute to not only the creation of ocean literate citizens but to the improvement of the economic state of the province. Retention 
of youth for employment purposes would help to build a younger, working population, which has been acknowledged as an issue within Nova Scotia (Guest et al., 2015; NSCBNE, 2014).

\section{Conclusion}

This research has examined Nova Scotia high school science curriculum to determine the degree of inclusion of the seven Ocean Literacy Principles. Results have indicated that, with the exception of the Oceans 11 course, these principles are largely lacking from high school science curricula. These findings are consistent with a considerable number of studies from Canada, United States, England, and South Africa (Ballantyne, 2004; Brody \& Koch, 1990; Cudaback, 2006; Cummins \& Snively, 2000; Guest, et al., 2015; Plankis \& Marrero, 2010) that have all indicated low levels of ocean knowledge among youth. The Ocean Literacy Principles were designed to inform and improve understanding of ocean concepts to help engage individuals in the sustainable use of this resource. This study indicates that students in Nova Scotia are not being provided with the opportunity in school to develop the skills necessary to make informed decisions regarding the health of the ocean, not only as a valuable resource, but as a lifeline for the planet. Without the inclusion of explicit references to the Ocean Literacy Principles within the curriculum, ocean education will continue to be inconsistent and marginalized in the classroom.

Limitations of this study included distance between school boards within Nova Scotia and time frame. Future research should explore these results further, examining the inclusion of Ocean Literacy Principles in other disciplines such as the social sciences and language arts. In addition, research focusing on different age groups, such as elementary, junior high, or university age students, may provide deeper insight into the inclusion of ocean education.

\section{Recommendations for the Future}

In consideration of these challenges, it is important to note that science curriculum documents can shift towards the inclusion of Ocean Literacy Principles. It is recommended that the Nova Scotia Department of Education alter science curriculum to include the explicit reference to Ocean Literacy Principles within the curriculum outcomes. The Oceans 11 course specifically should be realigned to reflect more of the Ocean Literacy Principles and include all fundamental concepts. While this would be a good start to improving the conditions of ocean education, this alone would not be enough to create ocean literate citizens. With the abundance of ocean related resources available in Nova Scotia there is the potential to include these resources in the education of students on potential career opportunities as well as developing ocean-based knowledge. Another recommendation for the improved development of ocean literate citizens would be for the Nova Scotia Department of Education to develop partnerships with government, universities, and ocean research facilities and within the ocean technology sector to fully expose students to the vast resources and opportunities that exist in Nova Scotia. In addition, appropriate training would have to be provided to educators, many of whom 
have no background in ocean science, so that the newly implemented curriculum would be effectively delivered.

\section{References}

APEF (Atlantic Provinces Education Foundation). (1998). Foundation for the Atlantic Canada science curriculum. Halifax, Nova Scotia: Department of Education.

Assaraf, O, Orion, N. (2005). Development of System Thinking Skills in the Context of Earth System Education. Journal of Research in Science Teaching, 42(5), 518-560.

Ballantyne, R. (2004). Young students' conceptions of the marine environment and their role in the development of aquaria exhibits. GeoJournal, 60(2), 159-63. https://doi.org/10.1023/b:gejo.0000033579.19277.ff

Belden N, Russonello J. Stewart \& American Viewpoint. (1999). Communicating About Oceans: Results of a National Survey. National survey conducted for The OCEANS Project. Washington DC: Belden, Russonello \& Stewart Research and Communications. http://www.brspoll.com/uploads/files/Oceans\%20summary. Pdf

Berchez, F.A.S., Ghilardi-Lopes, N.P., Correia, M.D., Sovierzoski, H.H., de Pedrini, A.G., Ursi, S., Kremer, L.P., de Almeida, R., Schaeffer-Novelli, Y., Marques, V., Brotto, D.S. (2016). Marine and coastal environmental education in the context of global climate changes - synthesis and subsidies for RioBentos (Coastal Benthic Habitats Monitoring Network). Brazil Journal of Oceanography, 64(2), 137-156. https://doi.org/10.1590/s1679-875920160932064sp2

Brody, M.J., Koch, H. (1990). An assessment of 4th-, 8th-, and 11th-grade students' knowledge related to marine science and natural resource issues. Journal of Environmental Education, 21(2), 16-26. https://doi.org/10.1080/00958964.1990.9941927

Castle, Z., Fletcher, S., McKinley, E., (2010). Coastal and Marine Education in Schools: constraints and opportunities created by the curriculum, schools and teachers in England. In: Ocean Yearbook. 24, 425-444. https://doi.org/10.1163/22116001$\underline{90000066}$

Cava, F., Schoedinger, S., Strang, C., and Tuddenham, P. (2005). Science content and Standards for Ocean Literacy: A Report on Ocean Literacy. (Retrieved from). http://coexploration.org/oceanliteracy/documents/OLit200405 Final Report.pdf.

CMEC (Council of Ministers of Education, Canada). (2001). The Development of Education in Canada. In response to the International Survey in Preparation for the Forty-Sixth Session of the International Conference on Education Geneva September 5-8, 2001.

Cudaback, C. (2011). What do college students know about the ocean? Eos, Transactions, American Geophysical Union, 87(40), 418-21. http://dx.doi.org/10.1029/2006EO400003.

Cummins, S., Snively, G. (2000). The Effect of Instruction on Children's Knowledge of Marine Ecology, Attitudes toward the Ocean, and Stances toward Marine Resource Issues. Canadian Journal of Environmental Education, 5(1), 305-326.

Eddy, T. (2014). One Hundred-fold Difference between Perceived and Actual Levels of Marine Protection in New Zealand. Marine Policy, 46, 61-67. https://doi.org/10.1016/j.marpol.2014.01.004

Fletcher, S., Potts, J. (2007). Ocean Citizenship: An emergent Geographical Concept. Coastal Management, 35, 511-524. https://doi.org/10.1080/08920750701525818

Fletcher, S., Potts, J., Heeps, C., Pike, K. (2009). Public Awareness of Marine Environmental Issues in the UK. Marine Policy, 33(2), 370-5. https://doi.org/10.1016/j.marpol.2008.08.0044 
Gough, A. (2017). Educating for the Marine Environment: Challenges for Schools and Scientists. Marine Pollution Bulletin, 124(2), 633-638. https://doi.org/10.1016/j.marpolbul.2017.06.069

Guest, H., Lotze, H., Wallace, D. (2015). Youth and the Sea: Ocean Literacy in Nova Scotia, Canada. Marine Policy, 58, 98-107. https://doi.org/10.1016/i.marpol.2015.04.007

Hoffman, M., Barstow, D. (2007). Revolutionizing Earth System Science Education for the 21st Century, Report and Recommendations from a 50-State Analysis of Earth Science Education Standards. TERC, Cambridge MA.

McKinley, E., Fletcher, S. (2012). Improving Marine Environmental Health through Marine Citizenship: A call for debate. Marine Policy, 36, 839-843. https://doi.org/10.1016/j.marpol.2011.11.001

Nova Scotia Department of Education. (1998). Foundation for the Atlantic Canada Science Curriculum. (Retrieved from). https://www.ednet.ns.ca/files/curriculum/camet/foundations-science.pdf

Nova Scotia Department of Education. (2012a). Atlantic Canada Science Curriculum: Oceans 11. Nova Scotia. Department of Education.

Nova Scotia Department of Education. (2012b). Atlantic Canada Science Curriculum: Science 10. Nova Scotia. Department of Education. (Retrieved from). https://www.ednet.ns.ca/files/curriculum/Science10-2012.pdf

NSCBNE (Nova Scotia Commission on Building our New Economy). (2014). Now or Never: An Urgent Call to Action for Nova Scotians. (Retrieved from). http://onens.ca/wp-con tent/uploads/Now-or-Never-Nova-Scotia-FinalReport-withResearch-Engage ment-Documentation.pdf

Ocean Literacy Network. (2013). Ocean Literacy: The Essential Principles and Fundamental Concepts of Ocean Sciences for Learners of All Ages. Version 2. First published June 2005, revised March 2013. Washington, DC: National Oceanic and Atmospheric Administration. (Retrieved from). www.oceanliteracy.net.

Plankis, B., Marrero, M. (2010). Recent Ocean Literacy Research in United States Public Schools: Results and Implications. International Electronic Journal of Environmental Education, 1(1), 21-46.

Province of Nova Scotia. (2011). Defined by the Sea: Nova Scotia's Oceans Technology Sector Present and Future. Halifax, Nova Scotia, Canada: Department of Economic and Rural Development and Tourism. http://novascotia.ca/econ/sectors/docs/Defined_by_the_seaNS_Oceans_Tech nology_Sector.pdf; 2011.

QSR International (2017). What is Qualitative Research? (Retrieved from). http://www.qsrinternational.com/what-is-qualitative-research.aspx

Schoedinger, S., Tran, L. U., Whitley, L. (2010). From the Principles to the Scope and Sequence: A Brief History of the Ocean Literacy Campaign. NMEA Special Report \#3. Ocean Springs, MS.

Scully, S. (2015). Marine People Partnership: The Challenges Needs and Opportunities for Strategic Workforce Development in the Greater Marine Industry. Halifax, NS: Institute for Ocean Research Enterprise (IORE)

Scully, S. (2016). Marine People Partnership: Student Intentions and Perceptions Survey. Report of Findings, Analysis and Recommendations. Halifax, NS: Institute for Ocean Research Enterprise (IORE)

Steel, B., Lovrich, N., Lach, D., Fomenko, V. (2005a). Correlates and Consequences of Public Knowledge Concerning Ocean Fisheries Management. Coastal Management, 33, 37-51. https://doi.org/10.1080/08920750590883105

Steel, B., Smith, C., Opsommer, L., Curiel, S., Warner-Steel, R. (2005b). Public Ocean Literacy in the United States. Ocean and Coastal Management, 48, 97-114. https://doi.org/10.1016/j.ocecoaman.2005.01.002 
Strang, C. (2008). Education for Ocean Literacy and Sustainability: Learning from Elders, Listening to Youth. Journal of Marine Education, 24(3), 6-10.

Tran, L. U., Payne, D., Whitley, L. (2010). Research on Learning and Teaching Ocean and Aquatic Sciences. NMEA Special Report \#3. Ocean Springs, MS.

UNESCO. (2014). Roadmap for Implementing the Global Action Programme on Education for Sustainable Development. UNESCO, Paris (Retrieved from). http://unesdoc.unesco.org/images/0023/002305/230514e.pdf.

Uyarra, M. C., Borja, A. (2016). Ocean Literacy a "new" socio-ecological concept for a sustainable use of the seas. Marine Pollution Bulletin, 104(1-2), 1-2. https://doi.org/10.1016/j.marpolbul.2016.02.060 